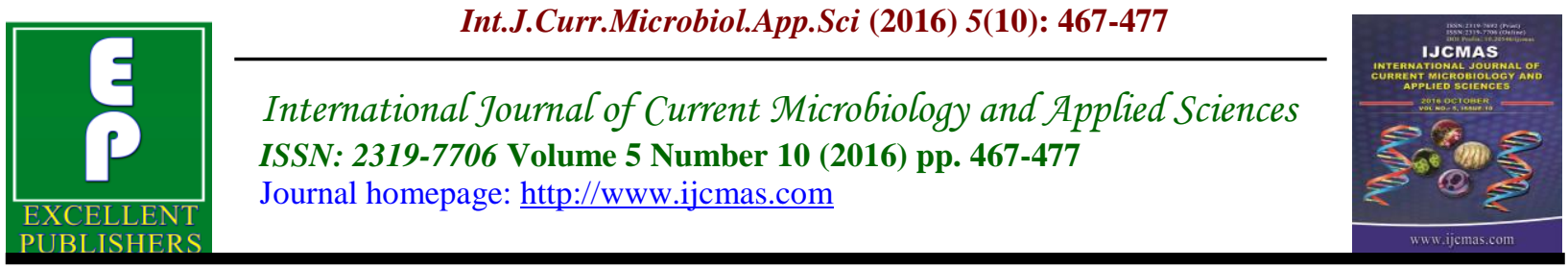

Original Research Article

http://dx.doi.org/10.20546/ijcmas.2016.510.053

\title{
The Effect of Lipid Components of Corn Vinasse on the Growth Intensity of Yeast Rhodosporidium diobovatum IMB Y-5023
}

\author{
Iuliia Ielchishcheva, Anatoliy Bozhkov*, Anatoliy Goltvianskiy and Natalia Kurguzova \\ Research Institute of Biology, V.N. Karazin Kharkiv National University, \\ Sq. Svobody, 4, 61022 Kharkiv, Ukraine \\ *Corresponding author
}

Keywords

Yeast, lipids, cornvinasse, Rhodosporidium diobovatum IMBY -5023 , growth intensity, biomass.

\begin{tabular}{l}
\hline Article Info \\
\hline Accepted: \\
17 September 2016 \\
Available Online: \\
10 October 2016
\end{tabular}

\section{A B S T R A C T}

It was studied the effect of lipid components of corn vinasse on the growth intensity of yeast Rhodosporidium diobovatum IMB Y - 5023. It was established that when cultured on the primary corn vinasse the yeast growth intensity was quite low, and in such form it cannot be used for industrial production of yeast biomass. For use of corn vinasse in industrial production of yeast biomass it must be preliminary prepared, using flotation or separation for dividing into fractions and, respectively, for removing of mechanical particles and some lipids, inhibiting the growth of Rhodosporidium diobovatum IMB Y - 5023, $\mathrm{pH}$ of corn vinasse must be $5.0-6.0$.After such vinasse modification, the yield of $R h$. diobovatum IMB Y5023 dry biomass was increased by $44 \%$ compared to primary medium, and at the same time $R h$. diobovatum IMB Y - 5023 actively assimilated the residual lipid components of corn vinasse, which provided quite intensive growth of $R h$. diobovatum IMB Y - 5023 culture.For optimal growth and high yield of Rhodosporidium diobovatum IMB Y - 5023 biomass on corn vinasse the amount of its lipids must be about $300 \mathrm{mg} / \mathrm{ml}$, and at the concentration of $400 \mathrm{mg} / \mathrm{ml}$ their growth is inhibited. Also, it was found that when the media contained lipids with concentrations from 50 to $400 \mathrm{mg} / \mathrm{ml}$ and without mechanical particles, yeast cells formed aggregates.

\section{Introduction}

Yeast Rhodosporidium diobovatum IMB Y

- 5023 refer to the carotene-accumulating species and they can accumulate up to 25 mg carotenoids per $1 \mathrm{~g}$ dry biomass. Our investigations demonstrated, that the most of $R h$. diobovatum IMB Y - 5023 carotenoids are represented by lycopene, $\beta$-carotene and astaxanthin (Ielchishcheva and Goltvianskiy, 2015). The literature evidence that some species of $R h$. diobovatum also synthesize torulin, torulorodin and $\gamma$-carotene (Buzzini et al., 2007; Yurkov et al., 2008). Together with carotenoids they contain protein, amino acids, vitamins, lipids, the amount of which can vary in biomass, depending on the cultivation conditions, organic acids (Munch et al., 2015), ubiquinone (Yurkov et al., 2008),

It was shown that under the optimal cultivation conditions $R h$. diobovatum IMB 
$\mathrm{Y}-5023$ can accumulate from 3 to $7-8 \mathrm{~g} / \mathrm{l}$ dry biomass (Goltvianskiy et al., 2015; Ielchishcheva and Goltvianskiy, 2015).

Therefore, $R h$. diobovatum IMB Y -5023 is the prospective object for industrial cultivation. One of the nutrient media, rich in sugars, can be wheat vinasse - waste of distilleries. Quite often the raw materials of distilleries can contain corn together with wheat. It is known, that corn is rich in fats (Belyea et al., 2004), which fall into the liquid fraction of vinasse. The effect of lipid components of corn vinasse on the growth intensity of Rh. diobovatum IMB Y - 5023 is still has not been investigated.

It is known, that yeast $R h$. diobovatum also refer to microorganisms, who can accumulate more than $20 \%$ lipids in their biomass, depending on the medium and cultivation conditions (Munch et al., 2015). Such microorganisms, who can accumulate significant amount of lipids, and who are of great interest as a source of oil for the synthesis of biodiesel (Sitepu et al. 2014), are Rhodosporidium toruloides (Xu et al., 2012), Rhodosporidium babjevae (Munch et al., 2015), Rhodotorula glutinis (Chi et al., 2011) and others. In the work of Munch et al., 2015 it was studied the effect of pour glycerine and glycerine, obtained from the waste of biodiesel production, as a single source of carbon, on accumulation of biomass and lipids by $R h$. diobovatum 08 225. It had been shown that when culturing on such media, therein limiting the amount of nitrogen, Rh. diobovatum $08-225$ had accumulated up to $14 \mathrm{~g} / \mathrm{l}$ biomass with lipid content up to $50 \%$ of the total cell mass.

Study of the effect of lipids on the growth intensity is of great interest not only from the viewpoint of preparation of industrial nutrient media, but also for clarifying the regulation mechanisms of yeast cells proliferation.
In the present work it was determined the effect of lipid components of corn vinasse on the growth intensity of $R h$. diobovatum IMB Y - 5023.

\section{Materials and Methods}

\section{Microorganisms and culture conditions}

The strain of basidiomycete yeast Rhodosporidium diobovatum IMB Y - 5023 was obtained from the Microorganisms Depositary of Institute of Microbiology and Virology, National Academy of Sciences of Ukraine.

The stock culture was supported on the agar medium (26\% of wort, $2 \%$ of agar). Before cultivation in the test liquid media it was obtained the inoculum for further cultivation. For this purpose the yeast culture was transferred from the agar slant into a liquid Ryder nutrient medium: $\mathrm{NH}_{4} \mathrm{NO}_{3}-2 ; \mathrm{FeSO}_{4} \times 7 \mathrm{H}_{2} \mathrm{O}-0.1 ; \mathrm{MgSO}_{4}-$ $0.75 ; \mathrm{KCl}-0.4 ; \mathrm{K}_{2} \mathrm{HPO}_{4}-0.1 ; \mathrm{KH}_{2} \mathrm{PO}_{4}(\mathrm{~g} / \mathrm{l})$; $2 \%$ of glucose as a carbon source (1 tube was rinsed with $10 \mathrm{ml}$ fresh medium and the obtained suspension was added to $50 \mathrm{ml}$ of liquid medium in $300 \mathrm{ml}$ flasks).

As experimental media were used:

1. Ryder (g/l): $\mathrm{NH}_{4} \mathrm{NO}_{3}-2 ; \mathrm{FeSO}_{4} \times 7 \mathrm{H}_{2} \mathrm{O}-$ $0.1 ; \mathrm{MgSO}_{4-}-0.75 ; \mathrm{KCl}-0.4 ; \mathrm{K}_{2} \mathrm{HPO}_{4}$ $0.1 ; \mathrm{KH}_{2} \mathrm{PO}_{4}-1 ;$ glucose -20 .

2. BY: wheat bran extract $3 \%$, yeast extract $1 \%$. The extract was obtained due to thermal treatment at $\mathrm{T}=132^{\circ} \mathrm{C}$ under the pressure $1.5 \mathrm{~atm}$. for 1.5 hours.

3. CV: distillery corn vinasse, obtained at Karavanovskiy distillery of Kharkiv region, Ukraine, $\mathrm{pH}=3.4$. 
4. $\mathrm{CV}$ with different value of $\mathrm{pH}$ (range from 3.4 to 7.0 ).

5. CV after dividing into 3 fractions with the help of sedimentation (for 3 hours with preliminary bringing of $\mathrm{pH}$ up to 6.5 $1 \mathrm{~N} \mathrm{NaOH}$. In this way the primary corn vinasse was divided into 3 fractions lower fraction (LF), containing large mechanical flakes-like particles, middle fraction (MF), containing some small mechanical particles; and top fraction (TF), which did not contain any mechanical particles).

6. BY with addition of corn oil with concentrations of 50,100,200, 300 and $400 \mathrm{mg} / \mathrm{ml}$ of medium.

\section{Conditions for yeast cultivation}

The flasks were inoculated with three-day yeast culture $(5 \mathrm{ml}$ of inoculum was added to $50 \mathrm{ml}$ of medium in $250 \mathrm{ml}$ flask), cultured for 3-4 days at $22^{\circ} \mathrm{C}$ on orbital shaker at $150 \mathrm{rpm}$, round the clock.

\section{Determination of growth dynamics and biomass yield of yeast}

The number of yeast cells was determined on 1-4 days of growth by direct counting of cells in the Gorjaev chamber on all test media. The growth intensity of the culture was expressed by the quantity of cells million/ml.On the $3 \mathrm{~d}$ day of the culture growth the yield of yeast dry biomass on the test media was determined. For this purpose the biomass was dried at the temperature of $105^{\circ} \mathrm{C}$ up to constant weight and expressed in $\mathrm{g} / \mathrm{l}$ of dry mass.

\section{Determination of the total lipids in the corn vinasse}

The total lipids content was determined in primary corn vinasse after centrifugation
(15 minutes, $10000 \mathrm{~g}$ ) and after removing of top lipid phase. To determine total lipids the mixtures of organic solvents: chloroform methanol $(1: 2, \mathrm{v} / \mathrm{v})$ and chloroform methanol $(1: 2: 0.8, \mathrm{v} / \mathrm{v})$ to prepared samples were added. The extract was evaporated to dryness and mineralized at $120 \mathrm{C}$ for 20 minutes in $98 \%$ sulfuric acid. Then, the samples were diluted with water and it was determined the extinction at $400 \mathrm{~nm}$ on the SF - 46 spectrophotometer(LOMO, Russia). The content of lipid fractions was calculated using the calibration curve and it was expressed in $\mu \mathrm{g} / \mathrm{ml}$ of sample.

\section{Statistical analysis}

All experiments were performed in three replicates. All results were statistically processed using STATISTICA 10 program. The statistical error and significant difference between the control and experiment were determined using nonparametric method of analysis.

\section{Results and Discussion}

The growth intensity of $R h$. diobovatum IMB Y-5023 on the test media

In the first set of experiments $R h$. diobovatum IMB Y-5023 was cultured on the classical Ryder medium with $2 \%$ glucose as a carbon source. During 24 hours of growth the number of $R h$. diobovatum IMB $\mathrm{Y}-5023$ cells had increased 3.7 times compared to the primary amount, during 48 hours -15.2 times, and after 72 hours -22 times (Table 1).

Therefore, the addition of glucose up to $2 \%$ to the Ryder medium had provided relatively good culture growth.

When Rh. diobovatum IMB Y -5023 cultured on the corn vinasse, it was appeared that after 24 hours of growth the number of 
yeast cells increased 7 - fold more than on Ryder medium, however, then, the intensity of growth increased with the less rate (by 11.7 and 19 times) after 48 and 72 hours, compared to the primary number of cells, respectively (Table 1).

The present results evidence that the growthdetermining components, contained in $\mathrm{CV}$, were actively assimilated by yeasts, but the medium was exhausted more quickly, then the Ryder medium.

The comparison of the growth intensity of $R h$. diobovatum IMB Y - 5023 (Table 1) with the other media allows to conclude, that the growth intensity on these media was relatively low.

For experimental verification of this fact $R h$. diobovatum IMB Y - 5023 was cultured on water extract of wheat bran BY, prepared as it was described in "Methods". It was found that on BY during 24 hours of growth the number of cells increased by 25 times, and after 48 and 72 hours - by 51 and 102 times, compared with the primary number, respectively (Table 1).

Therefore, the growth intensity of $R h$. diobovatum IMB Y - 5023 on $\mathrm{CV}$, which is the waste of alcohol industry, is lower compared to BY, and in such form it cannot be used for yeast production.

Low growth intensity of $R h$. diobovatum IMB Y-5023 on CV, compared with BY, can be explained by the low primary $\mathrm{pH}$ value of this medium, it was 3.4. Thereby, in the further set of experiments it was determined the yield of $R h$. diobovatum IMB Y-5023 dry biomass when cultured on the corn vinasse with various $\mathrm{pH}$ values. It was established that under $\mathrm{pH} 5.0-6.5$ the growth intensity of yeast was 34\% more compared to the primary medium, and under
$\mathrm{pH} 7.0$ their growth intensity decreased again by $28 \%$ compared to $\mathrm{pH} 5.0$ (Fig. 1).

Consequently, bringing $\mathrm{pH}$ of $\mathrm{CV}$ up to 5.0 -6.5 provide intensification of their growth, however, they grew significantly slower, compared with BY medium. Lower growth intensity of $R h$. diobovatum IMB Y -5023 on $\mathrm{CV}$, compared with $\mathrm{BY}$ medium, may be connected with some more factors: lack of sugars and other nutrients, poor assimilation of corn vinasse nutrients, presence of factors, inhibiting yeast growth. Such factors can include lipids, since it is known that the corn vinasse contains more lipids(Belyea et al., 2004), compared with the wheat bran extract (Goltvianskiy et al., 2015).

Dividing of the corn vinasse into three fractions and the growth intensity of $R h$. diobovatum IMB Y-5023 on these fractions

Since the corn vinasse has heterogeneous composition, it was divided into 3 constituent fractions. After bringing $\mathrm{pH}$ up to $6.0-6.5$ and settling for an hour with a liquid column height of $15 \mathrm{~cm}$, it was well divided into 3 fractions.

The top fraction (TF) did not contain mechanical particles, the middle fraction (MF) contained many small mechanical residues - corn seeds and the lower fraction (LF) contained a lot of large mechanical particles. Yeast growth intensity on the 3 fractions was different.

Thus, the number of yeast cells during 2 days of cultivation on LF was increased by 2 times, compared to the primary amount, and further it remained the same (Fig. 2A)

The yeast grew much better on MF. After 3 days the number of cells on this fraction increased by 17.2 times (Fig. 2A). 
However, the best growth of Rh. diobovatum IMB Y - 5023 was noticed on TF. The number of cells already after 1 day of growth was by 16 times more than the primary number, and after 2 and 3 days of growth it was increased by 63 and 77 times, respectively, as it was on BY (Fig. 2A).

The various rate of growth of $R h$. diobovatum IMB Y - 5023 on the different fractions of $\mathrm{CV}$ is evidenced by the yield of yeast dry biomass on the 3 days of cultivation (Fig. 2B).

It must be noticed, that the yield of yeast dry biomass, when cultured on the corn vinasse on TF after removing of mechanical particles and bringing $\mathrm{pH}$ up to $5.0-6.5$ was almost the same, as on BY, and it was $4.5-5.0 \mathrm{~g} / 1$ dry yeast biomass during 3 days of growth.

\section{The total lipids determination in 3 fractions of the corn vinasse}

As it was noted, corn is rich in lipids and their amount can remain unchanged in the vinasse. Most lipids were detected in TF and their content was $334 \mathrm{mg} / \mathrm{ml}$, and in the middle and lower fractions it was by 3 times less (Fig. 3A).

It should be noted, that there was no direct relationship between the lipid content in the vinasse and the growth intensity in MF and LF. Thus, MF contained $100.3 \mathrm{mg} / \mathrm{ml}$ lipids, and LF $149.9 \mathrm{mg} / \mathrm{ml}$, in this case the growth intensity of $R h$. diobovatum IMB Y -5023 in MF was higher, than in LF.

During the next set of experiments the content of lipids in TF before and after 3 days of yeast cultivation was determined. It was found that after 3 days of yeast growth, the content of lipids in TF was decreased by
2.5 times, compared to their primary amount (Fig. 3B).

Hence, Rh. diobovatum IMB Y - 5023 yeast actively assimilated the lipid components of corn vinasse.

Additionally, it was found, that namely in TF of corn vinasse, contained more than 300 $\mathrm{mg} / \mathrm{ml}$ lipids and where the yeast culture grew intensively, the cells of $R h$. diobovatum IMB Y - 5023 formed aggregates, which were absent in the control culture (CV) and in the samples, growing on $\mathrm{MF}$ and LF.

Therefore, removing of mechanical particles in $\mathrm{CV}$ and its high lipid content provided intensive growth of yeasts, that didn't differ from the growth of culture on BY. It may be assumed, that presence of such amount of lipids in the vinasse stimulated the growth of Rh. diobovatum IMB Y - 5023 culture.

To verify this fact, on the next stage of the work it was determined the growth intensity of $R h$. diobovatum IMB Y -5023 on BY, adding different amounts of corn lipids. When selecting the concentrations of lipids we based on the principle that the fraction of corn vinasse (TF), which had the highest yield of yeast biomass, contained about 300 $\mathrm{mg} / \mathrm{ml}$ lipids.

The lipid suspensions were prepared on BY with concentrations of 50,100, 200, 300 and $400 \mathrm{mg} / \mathrm{ml}$ lipids.

Growth intensity of Rh. diobovatum IMB Y5023 culture on BY, adding of $50 \mathrm{mg} / \mathrm{ml}$ corn lipids, lightly increased only in the beginning of cultivation: by $30-32 \%$ after 24 and 48 hours, compared to the control (Fig. 4). 
The rise of corn lipid content in the medium up to $100 \mathrm{mg} / \mathrm{ml}$ increased the growth intensity by $60,41,12$ and $18 \%$ after 24 , 48, 72 and 96 hours, respectively (Fig. 4).

The greatest impact on stimulation of culture growth was obtained after addition of 300 $\mathrm{mg} / \mathrm{ml}$ corn lipids to the culture medium. Thus, the number of cells was increased by $71,65,26,36 \%$ compared to the control after 24, 48, 72 and 96 hours, respectively (Fig. 4). The rise of corn lipid content in the medium up to $400 \mathrm{mg} / \mathrm{ml}$ further slightly slowed down the culture growth, compared to the concentration of $300 \mathrm{mg} / \mathrm{ml}$ (Fig. 4).

It must be noticed, that when $R h$. diobovatum IMB Y - 5023 cultured on these media with addition of corn lipids with concentrations from 50 to $400 \mathrm{mg} / \mathrm{ml}$, cells of $R h$. diobovatum IMB Y - 5023 formed aggregates (Fig. 5), as in TF.

Hence, corn lipids stimulate growth of $R h$. diobovatum IMB Y-5023, the greatest impact of stimulation was demonstrated during the first $24-48$ hours of cultivation. The optimal concentration of lipids for the yeast growth is $300 \mathrm{mg} / \mathrm{ml}$.

It is known, that the growth of microorganisms as well as the other organisms is a complex integrative process. Under the integrative processes of growth we mean the creation of "single" functional dynamic system between the organism's metabolism and the components of environment, and more precisely, the organism's microenvironment.

How had this unity been created? On the one hand, due to the presence of alternative metabolic pathways, metabolism forms such metabolic pattern, which provides its selfregulation in the particular environment, i.e. the organism utilizes that components for growth and reproduction, which surround it at the moment. On the other hand, the organism as the open system, excreting metabolites in the environment, dynamically "adjust" its microenvironment under the selected metabolic strategy of functioning. As a result, the metabolic system of organism and the components of microenvironment form a single dynamic system - "SDS". The faster the SDS will be formed, the shorter will be the lag-period, and the more effectively SDS will be formed, the higher will be the rate of culture reproduction. In that case, if SDS will not be formed because of "incompatibility" between the possibilities of metabolism and components of microenvironment, the culture will die.

The effectiveness of SDS forming depends on many factors and conditions. Conceptually, it may be highlighted only some of them: the characteristics of genotype, i.e. structural and dynamic organization of the genetic system. The most important characteristic of SDS is the presence of genes that provide alternative pathways, i.e., metabolism of sugars, lipids etc. The second feature of the genetic system is its instability or dynamic adaptive conversion. As it is known, the instability of microbial genome is provided by plasmids (Bibb et al., 1978; Lichtetal, 2001), transposons (Nagyand Chandler, 2004) and high mutability as well as horizontal gene transfer (Craigetal, 2002).

Epigenetic mechanisms play an equally important role in the "organism environment" "unity". Change of culture medium was shown to influence on the characteristics and the extent of DNA methylation (Nicholson and Low, 2000), and other epigenetic mechanisms, that are inadequate studied in microorganisms. 
The next important factor is the characteristics of metabolic regulation, and more precisely, the amount of alternative metabolic pathways in a single organism. It is known that yeast can simultaneously assimilate various substrates (Marovaetal, 2011).This is also evidenced by the fact, that the same species or strain can grow with the same rate on different substrates (Buzziniand Martini, 1999). At the same time they accumulate different amount of metabolites. Thus, Rh. diobovatum IMB Y 5023 can accumulate a similar biomass per time unit on BY medium and corn vinasse (Fig.2B). Previously, it had been shown that $R h$. diobovatum IMB Y - 5023 accumulate different amount of carotenoids and other metabolites on different media (Yurkov et al., 2008; Ielchishcheva and Goltvianskiy, 2015). The effective use of alternative metabolic pathways by yeast $R h$. diobovatum IMB Y-5023 is evidenced by the studies of Munch et al. (Munch et al., 2015). These authors had demonstrated that $R h$. diobovatum $08-225$ can be cultivated on pure glycerol as a single source of carbon. In such case, its growth intensity was high - they accumulated up to $14 \mathrm{~g} / \mathrm{l}$ biomass with lipid content up to $50 \%$. This yeast can be a promising source of biodiesel (Chietal, 2011; Xu et al., 2012; Sitpuetal, 2014).

Table.1 The number of the $R h$. diobovatum IMB Y-5023 cells when cultured during 72 hours on different media. The average values from 3 independent experiments are presented

\begin{tabular}{ccccc}
\hline \multirow{2}{*}{ Culture media } & \multicolumn{4}{c}{ Cultivation time, hours } \\
\cline { 2 - 5 } & 0 & 24 & 48 & 72 \\
\hline Ryder & $5.4 \pm 0.27$ & $20.4 \pm 1.02$ & $82.3 \pm 4.11$ & $120.9 \pm 6.04$ \\
\hline CV & $5.4 \pm 0.27$ & $38.1 \pm 1.91$ & $63.2 \pm 3.16$ & $103.7 \pm 5.18$ \\
\hline BY & $5.4 \pm 0.27$ & $134.5 \pm 6.72$ & $279.6 \pm 13.98$ & $555 \pm 27.75$ \\
\hline
\end{tabular}

Fig.1 The yield of $R h$. diobovatum IMB Y-5023 dry biomass when cultured on the corn vinasse (CV) with $\mathrm{pH}$ from 3.4 to 7.0 .

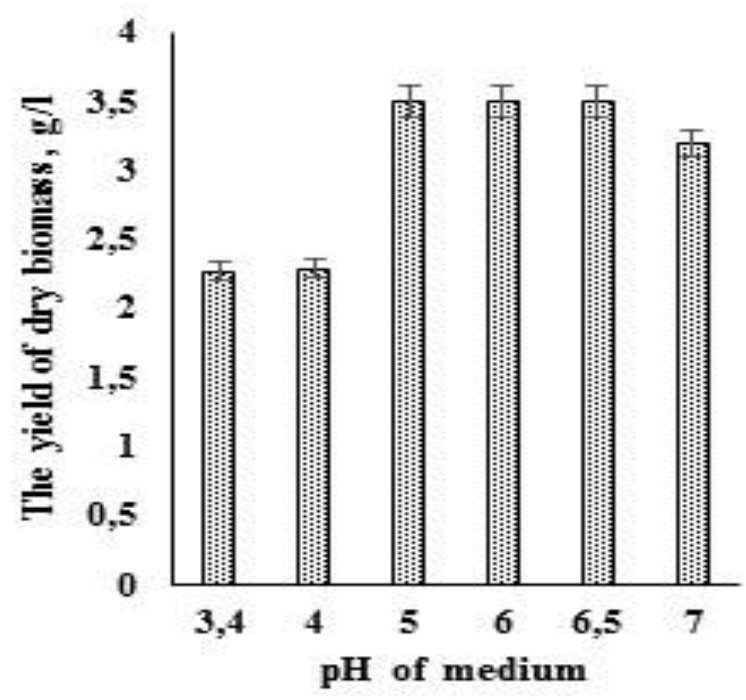


Fig.2 The intensity of growth of Rh. Diobovatum IMB Y-5023 on the different fractions (LF. MF. TF) of the corn vinasse (A); The yield of Rh. diobovatum IMB Y-5023 dry biomass when cultured on the primary medium $(\mathrm{CV})$, on different fractions of the corn vinasse and on the bran extract (BY) on the 3d day of growth (B)

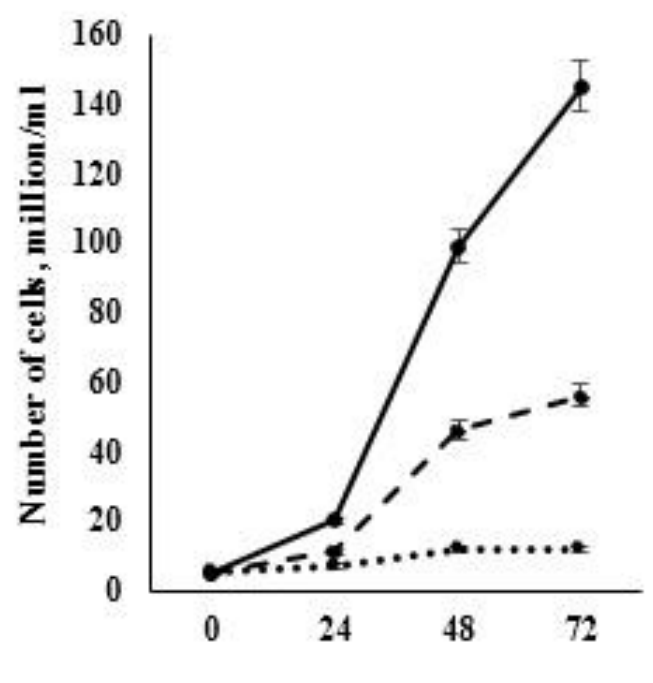

A

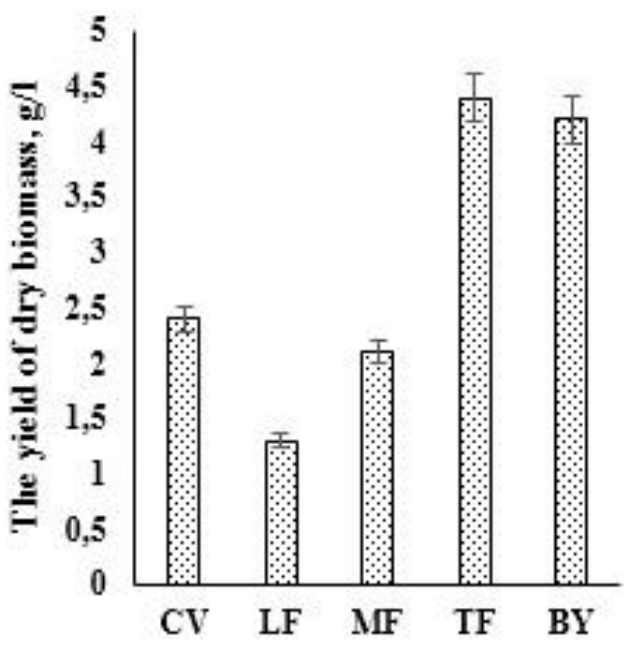

B

Cultivation time, hours

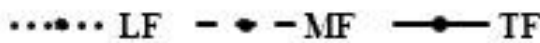

Fig.3 The content of total lipids in the different fractions of corn vinasse (CV) (A) and the content of total lipids before and after cultivation of Rh. diobovatum IMB Y-5023 in the top fraction (TF) (B)

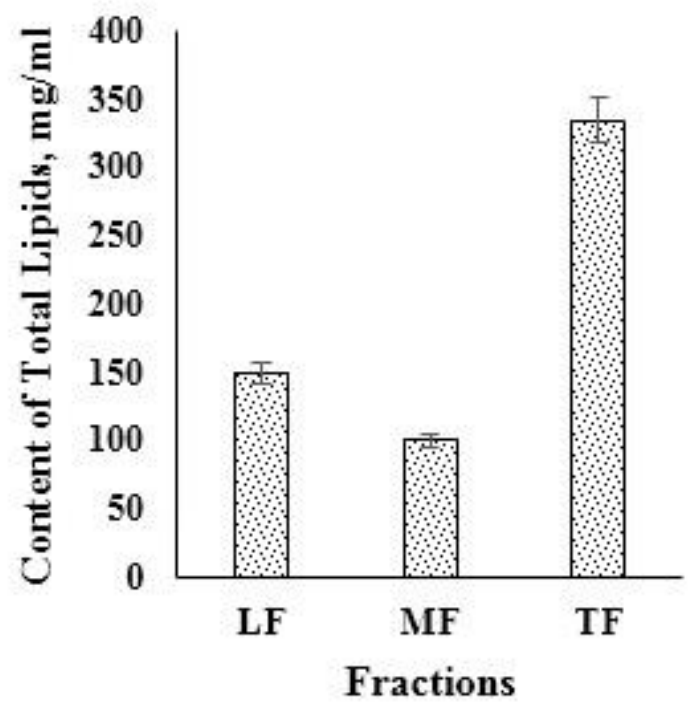

$\mathbf{A}$

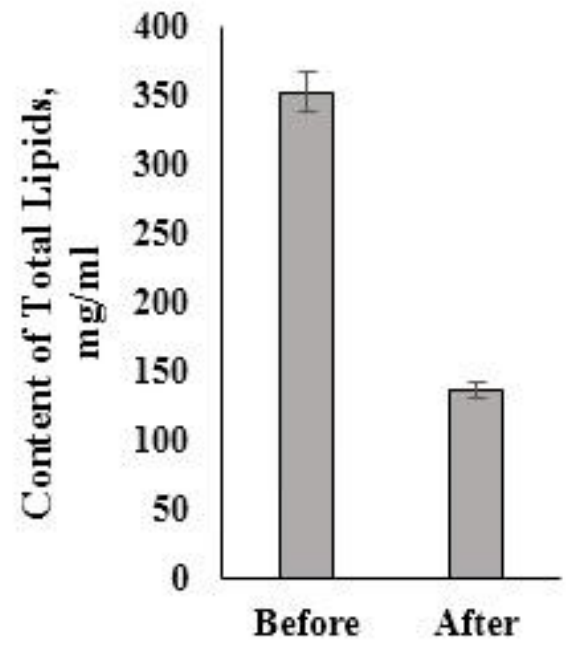


Fig.4 The growth intensity of $R h$. diobovatum IMB Y-5023 culture onthe bran extract(BY), adding corn lipids with concentrations of 50, 100, 200, 300 and $400 \mathrm{mg} / \mathrm{ml}$

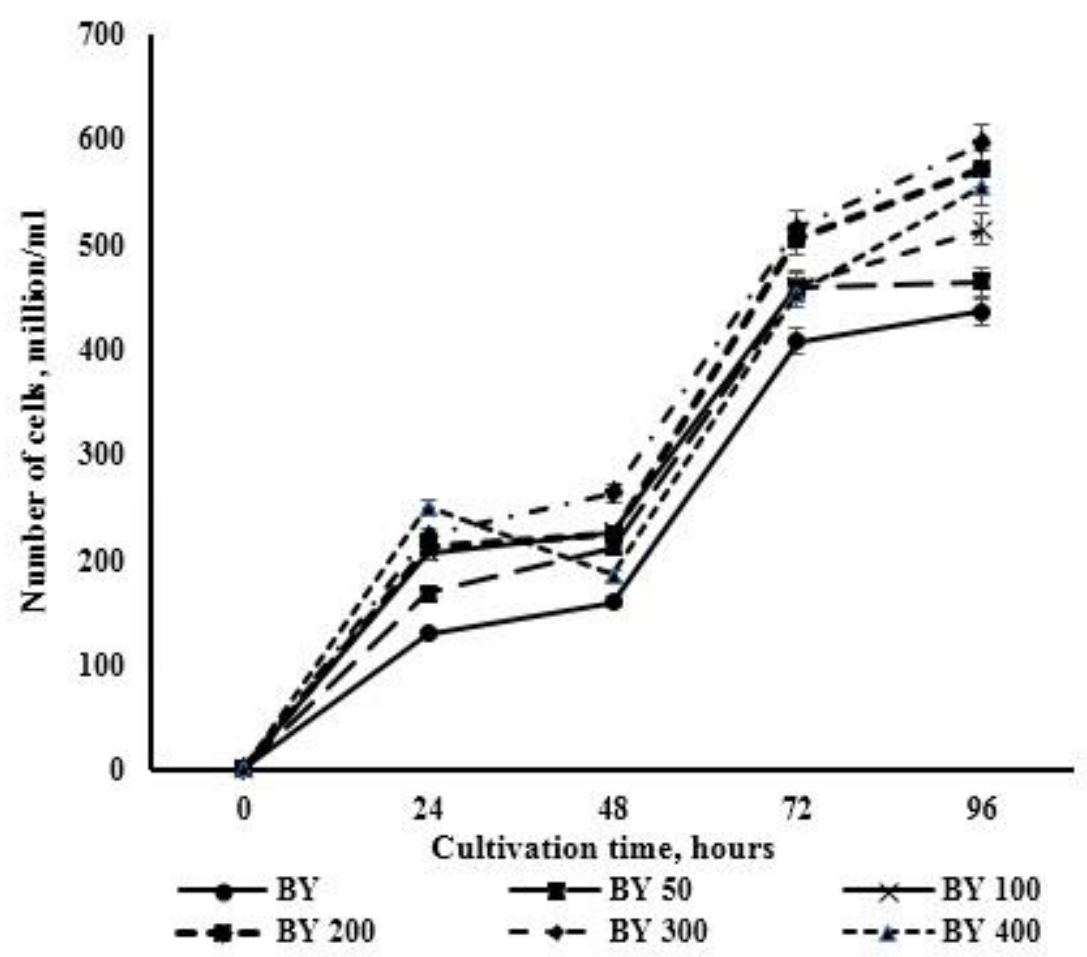

Fig.5 Formation of $R h$. diobovatum IMB Y-5023 cell aggregates when cultured on the bran extract (BY) with addition of corn lipids with concentrations from 50 to $400 \mathrm{mg} / \mathrm{ml}$

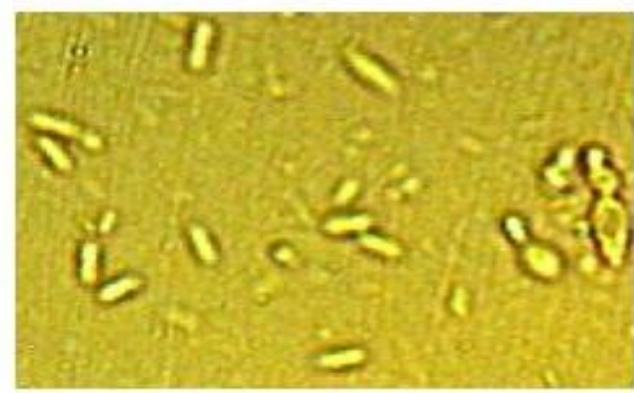

BY

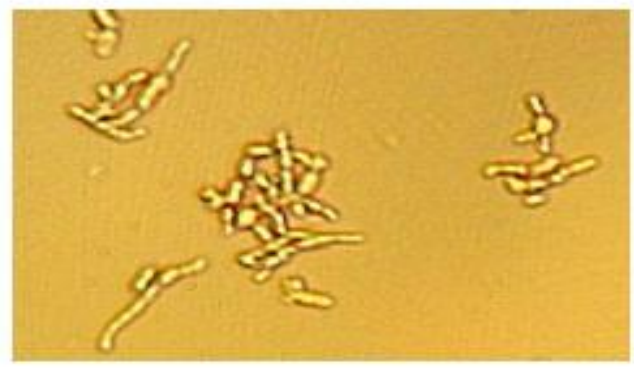

BY 200

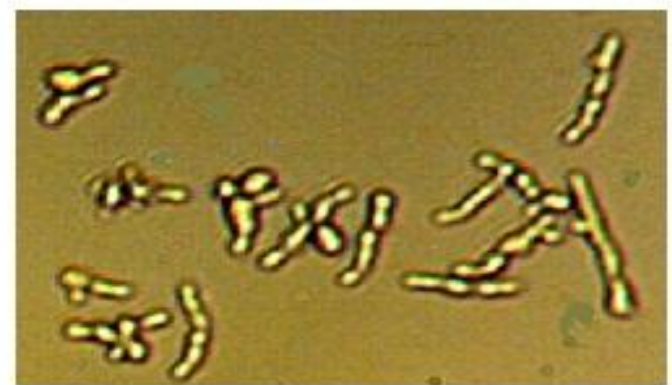

BY 50

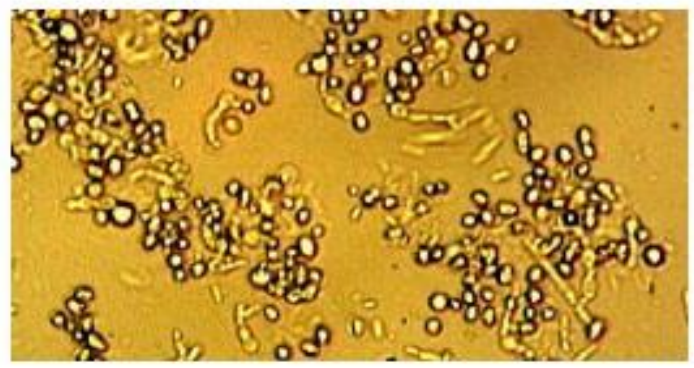

BY 400 
The ability of yeast $R h$. diobovatum IMB Y5023 to assimilate lipids is evidenced by the results of the present study. It should be noted, that there is a well-defined dose dependence between the increase of culture growth intensity and the lipid content in the culture medium (Fig. 4).

The presence of "zone" of saturation by lipid components may indicate the presence of genetic and metabolic species limitations.

Together with the genetic and metabolic characteristics of SDS formation, the same role, and, probably, defining role belong to characteristics of microenvironment. It should be noted, that the most important feature of the microenvironment is 1 - high rate of parameters changing - its physical and chemical characteristics $(\mathrm{pH}$, viscosity, osmolality, temperature, etc.), 2 - formation of gradients around the functionally active cells. These are the gradients of medium components, which are formed due to the opposite direction of flows of exometabolites excretion and nutrients absorption, temperature gradients, cell heat generation, $\mathrm{pH}$ gradients, etc. and finally, the presence of growth inhibitors and promoters in medium for particular representative of microorganisms.

The results of the present work allow to assume that together with necessary nutrients for $R h$. diobovatum IMB Y-5023 corn vinasse contains the inhibitors of yeast growth. Thus, after its dividing into fractions, the components of heavy fraction of medium did not "provide" the effective formation of SDS, i.e. the intensity of biomass accumulation. Thus, despite the slight differences in the lipid content in fraction and heavy fraction, the growth intensity of $R h$. diobovatum IMB Y -5023 differed strongly (Fig. 2,3).
In conclusion, therefore, yeast $R h$. diobovatum IMB Y-5023 can grow on media rich in lipids, and corn vinasse after preliminary preparation (dividing by flotation or separation and bringing of $\mathrm{pH}$ up to 5 - 6.5) can be used for industrial production of yeast biomass rich in carotenoids and other biologically active substances.

\section{References}

Belyea, R.L., Rausch, K.D., Tumbleson, M.E. 2004. Composition of corn and distillers dried grains with soluble from dry grind ethanol processing. Biores. Technol., 94: 293-298.

Bibb, M.J., Ward, J.M., Hopwood, D.A. 1978. Transformation of plasmid DNA into Streptomyces at higt frequency. Nature, $\quad 274: \quad 398 \quad-\quad 400$. doi:10.1038/274398a0.

Buzzini, P., Innocenti, M., Turchetti, B., Libkind, D., van Broock, M., Mulinacci, N. 2007. Carotenoid profiles of yeasts belonging to the genera Rhodotorula, Rhodosporidium, Sporobolomyces and Sporidiobolus. Can J Microbiol., 53: 1024-1031.

Buzzini, P., Martini, A. 1999. Production of carotenoids by strains of Rhodotorula glutinis cultured in raw materials of agro-industrial origin. Biores. Technol., 71: 41-44.

Chi, Z., Zheng, Y., Jiang, A., Chen, S. 2011. Lipid production by culturing oleaginous yeast and algae with food waste and municipal wastewater in an integrated process. Appl. Biochem. Biotech., 165: 442-453.

Craig, N.L., Craigie, R., Gellert, M., Lambowitz, A.M. (Eds.). Mobile DNAII, ASM Press, Washington, DC, 2002.

Goltvianskiy, A., Ielchishcheva, Iu., Stachowiak, B., Szwengiel, A., 
Bozhkov, A. 2015. Preculture of Pleurotus ostreatus increases the yield of yeast biomass. Int. J. Curr. Microbiol. Appl. Sci., 4: 124-133.

Ielchishcheva, Iu., Goltvianskiy, A. 2015. Growth and carotenoids content of yeast Rhodosporidium diobovatum IMBY-5023 in natural and synthetic media.Visnyk of the Lviv University. Series Biol., 70: 221-229.

Licht, T.R., Laugesen, D., Jensen, L.B., Jacobsen, B.L. 2002. Transfer of the Pheromone-Inducible Plasmid pCF10 among Enterococcus faecalis Microorganisms Colonizing the Intestine of Mini-Pigs. Appl. Environ. Microbiol., 68(1): 187-193. DOI: 10.1128/AEM.68.1.187-193.2002.

Marova, I., Certik, M., Brejerova, E. 2011. Production of enriched biomass by carotenogenic yeasts - application of whole-cell yeast biomass to production of pigments and other lipid compounds: Biomass - Detection, Production and Usage: In Tech., 345384.

Munch, G., Sestric, R., Sparling, R., Levin, D.B., Cicek, N.2015. Lipid production in the under characterized oleaginous yeasts, Rhodosporidium babjevae and Rhodosporidium diobovatum, from biodiesel derived waste glycerol.
Biores. Technol., 185: 49-55. doi: http://dx.doi.org/10.1016/j.biortech.20 15.02.051.

Nagy, Z., Chandler, M. 2004. Regulation of transposition in bacteria. Res. Microbiol., 155: 387-398.

Nicholson, B., Low D. 2000. DNA methylation-dependent regulation of Pefexpression in Salmonella typhimurium. Mol. Microbiol., 35(4): $728-742$.

Sitepu, I.R., Garay, L.A., Sestric, R., Levin, D., Block, D.E., Bruce German, J., Boundy-Mills, K.L. 2014. Oleaginous yeasts for biodiesel: current and future trends in biology and production. Biotechnol. Adv., 32: 1336-1360.

Xu, J., Zhao, X., Wang, W., Du, W., Liu, D. 2012. Microbial conversion of biodiesel byproduct glycerol to triacylglycerols by oleaginous yeast Rhodosporidium toruloidesand the individual effect of some impurities on lipid production. Biochem. Eng. J., 65: 30-36.

Yurkov, A.M., Vustin, M.M., Tyaglov, B.V., Maksimova, I.A., Sineokiy, S.P. 2008. Pigmented basidio-mycetous yeasts are a promising source of carotenoids and ubiquinone Q10. Microbiol., 77: 5-10.

\section{How to cite this article:}

Iuliia Ielchishcheva, Anatoliy Bozhkov, Anatoliy Goltvianskiy and Natalia Kurguzova. 2016. The Effect of Lipid Components of Corn Vinasse on the Growth Intensity of Yeast Rhodosporidium diobovatum IMB Y-5023. Int.J.Curr.Microbiol.App.Sci. 5(10): 467-477. doi: http://dx.doi.org/10.20546/ijcmas.2016.510.053 